\title{
Garin Dowd, Abstract Machines. Samuel Beckett and Philosophy after Deleuze and Guattari
}

\section{Stefano Genetti}

\section{Q OpenEdition}

1 Journals

\section{Edizione digitale}

URL: http://journals.openedition.org/studifrancesi/7712

DOI: 10.4000/studifrancesi.7712

ISSN: 2421-5856

\section{Editore}

Rosenberg \& Sellier

\section{Edizione cartacea}

Data di pubblicazione: 1 décembre 2009

Paginazione: 667

ISSN: 0039-2944

\section{Notizia bibliografica digitale}

Stefano Genetti, «Garin Dowd, Abstract Machines. Samuel Beckett and Philosophy after Deleuze and Guattari», Studi Francesi [Online], 159 (LIII | III) | 2009, online dal 30 novembre 2015, consultato il 09 janvier 2021. URL: http://journals.openedition.org/studifrancesi/7712 ; DOI: https://doi.org/10.4000/ studifrancesi.7712

Questo documento è stato generato automaticamente il 9 janvier 2021.

\section{(c)}

Studi Francesi è distribuita con Licenza Creative Commons Attribuzione - Non commerciale - Non opere derivate 4.0 Internazionale. 


\title{
Garin Dowd, Abstract Machines. Samuel Beckett and Philosophy after Deleuze and Guattari
}

\author{
Stefano Genetti
}

\section{NOTIZIA}

GARIN DOWD, Abstract Machines. Samuel Beckett and Philosophy after Deleuze and Guattari, Amsterdam-New York, Rodopi, 2007 («Faux titre», 295), pp. 319.

1 In ragione della sua densità concettuale e metacritica e nonostante gli ampi preamboli teorici, è questo un libro esigente ma ricco di suggestioni, e documentatissimo, come attesta la vasta bibliografia che precede l'indice analitico. Riprendendo in parte, rivisti e amalgamati, saggi pubblicati in rivista, l'A. si inserisce in maniera originale nella tradizione degli studi beckettiani di impostazione filosofica: interpretazioni basate sugli influssi assimilati e parodiati o sovvertiti da Beckett, repertori di filosofemi ricorrenti, ma anche riletture in chiave umanistica o postmodernista ad opera di pensatori, da Adorno, Ba-taille e Blanchot a Badiou (sulla critica del "Contre Deleuze" di quest'ultimo ci si sofferma alle pp. 192-200 e 219-223). L'approccio qui adottato, pur sfruttandone le risorse, problematizza la categoria dell'intertestualità poiché un convergere di questioni non si pone in termini di influenze dirette, bensì nell'ambito di uno sperimentale ripensamento dei rapporti tra discorso filosofico e letterario in quanto strumento ermeneutico insieme destabilizzante e stimolante. Tale ripensamento è guidato dagli scritti di Gilles Deleuze, con e senza Félix Guattari, a iniziare, ma senza limitarvisi, da quelli dedicati a Beckett o ad altri scrittori (anzitutto Proust e Kafka): Beckett e la filosofia, insomma, après più che d'après Deleuze e Guattari.

2 Sul flusso di riverberi e reciproche alter-azioni che caratterizza l'«interanimation of philosophy and literature» (p. 27) nell'incontro della scrittura beckettiana col (non) filosofare di Deleuze (e Guattari) verte il primo capitolo, laddove i successivi gravitano 
attorno a questioni più circoscritte. Nel secondo capitolo, il pensiero di Spinoza, rivisitato da Deleuze e Guattari, relativamente alle dialettiche di caos e forma e di unità e molteplicità induce l'A. a riconoscere nel protagonista di Murphy un antecedente dei corpi ammassati nel cilindro di Le Dépeupleur, le cui deambulazioni configurano meccanismi irriducibili al meccanicismo tecnologico. Nel terzo, sulla scia del dibattito neoplatonico su microcosmo e macrocosmo, si tratta della monadologia leibniziana 'pervertita' da Deleuze e della trilogia beckettiana, segnatamente degli inventari concettuali di Malone e dell'astrazione e dislocazione del corpo organico in L'Innommable. Fin dal titolo, Comment c'est sembra porre un quesito ontologico: nella quarta sezione, si interrogano le aporie del soggetto (narratore/narrato, testimone/ scriba, torturatore/vittima) e le discontinue immagini di una vita superiore che illuminano il suo trascinarsi nel fango sartrianamente visqueux della pura orizzontalità, mostrando come nelle tre parti del romanzo non si elabori se non ciò che Deleuze chiama una «synthèse disjonctive» (p. 170), che resiste al tribunale della ragione e dove ogni giudizio rimane sospeso. Nel quinto capitolo, si registra il collasso dell'intenzionalità fenomenologica e il fallimento della correlazione tra essere e rappresentazione in Cap au pire: debilitazione del dire e offuscamento dell'immagine interagiscono rendendo cieca la parola, muta la visione. Lo scritto di Deleuze sulle formule poetiche riassuntive della filosofia kantiana viene applicato nel sesto capitolo a un'analisi del motivo spazio-temporale della soglia che, a partire dai versi di je suis ce cours de sable qui glisse, si espande all'insieme degli scritti di Beckett: vestigio metaforico dell'indiscernibilità della voce e della labilità del senso, la soglia, da luogo di transizione, diventa a-topos, «espace quelconque» (p. 243) e agente di deterritorializzazione, dove la negoziazione si fa fluttuazione e la bi-direzionalità disorientamento.

3 A emergere è una concezione rizomatica, nomadica e molecolare dell'opera, dove centrale risulta l'idea di macchina astratta, intesa come assemblaggio materico e mobile di funzioni diagrammatiche e differenziali, di tensori espressivi che agiscono nell'immanenza testuale, al di là del loro spessore significante o simbolico e delle nozioni trascendenti di forma e sostanza. Sulla scia dell'interdisciplinarietà connaturata al pensiero della differenza e della ripetizione, l'A. esplora la soglia porosa tra letteratura e filosofia, rilanciando alla letteratura, attraverso Beckett, la sfida lanciata dal pensare di Deleuze e Guattari all'immagine di pensiero in quanto dominante antropocentrica della tradizione filosofica occidentale. 